\title{
COMPARATIVE TESTS ON SINGLE-PHASE ALTERNATING-CURRENT COMMUTATOR MOTORS.
}

\author{
By E. A. Richards, B.Sc.Eng., Graduate, and D. Dunham, B.Sc.Eng., Student.
}

(Paper read bcfore the Students' Section 7th May', 1913.)

The following paper consists mainly of a record of experiments carried out in the laboratories of the City and Guilds Engineering College (London) on alternatingcurrent commutator motors, the object of these tests being to compare the performances of the same machine when running as an Atkinson, Fynn, Latour-Winter-Eichberg, or synchronous motor. The last mentioned is of course a constant-speed machine, and the Atkinson and Fynn motors nearly so, whilst the Latour-Winter-Eichberg motor has a series characteristic.

As in the case of continuous-current motors these machines may be made to have either a series or shunt characteristic. Traction motors are naturally of the series type, and on account of the large demand for this type of motor much work has been done in perfecting them, with the result that they are now established as commercial machines.

Although Mr. Fynn and others have written papers dealing with commercial forms of the alternating-current shunt commutator motor, these motors have only recently come into extended practical use. They are suitable for many classes of work, such as the driving of machines, lifts, etc., where a larger starting torque is required than can be obtained with a single-phase induction motor, and they are particularly valuable in cases where speed regulation is required. For these reasons they should have a wide field of usefulness, in spite of the difficulties which have to be overcome in their design.

With the exception of tests in which the authors assisted Mr. F. Creedy on a motor of his own design, the tests here described!were all carried out on a Fynn motor built by the Alioth :Company of Basle, and rated at 140 volts 57 amperes at r,430 r.p.m. The rotor of this machine is an ordinary continuous-current series-wound armature with a commutator of II 7 segments. There are also four slip-rings connected to equidistant points in the winding. The commutator carries four sets of brushes displaced $90^{\circ}$ electrically from one another. The stator is built up of laminations and carries three distinct windings disposed in slots :-

(a) A 4-pole partially distributed winding termed in this paper the main or transformer winding, $S_{s}$;

(b) A similar but smaller winding displaced half a pole pitch from $(a)$ and termed the auxiliary or starting winding, $\mathrm{S}_{2}$;

(c) A compensating winding, $S_{3}$, of a few turns only, placed in the same slots as the main winding.

The ends of these windings are brought out to separate terminals, enabling the motor to be connected in various ways, in order to carry out the tests described below.

The motor was first tested as an Atkinson motor, connected as shown in Fig. I $(a)$. For simplicity the motor has been considered throughout as a two-pole machine, in which case the four sets of brushes would be equally spaced round the commutator. The Atkinson motor is not self-starting, and so it is necessary to connect it as a repulsion motor as shown in Fig. I (b) to start up, and switch over to the Atkinson connections when running.

At starting, then, the current in the main winding $S_{x}$ induces a current in the short-circuit axis $\mathbf{A ~ A}$ by transformer action. This secondary current in conjunction with the field due to the winding $S_{2}$ produces a torque, the direction of which depends on the direction of con. nection of $S_{2}$. When the motor is running a back E.M.F. is induced along the $\mathrm{AA}$ axis due to the cutting of the lines of the field produced by $\mathrm{S}_{2}$ by the rotor conductors. This E.M.F. opposes the secondary transformer current and so determines the speed of the motor for any given torque. The repulsion motor has, of course, nearly a series characteristic. The rotor conductors also cut the field due to $S_{1}$, and an E.M.F. is thereby produced at the brushes B B. If these brushes are short-circuited when the motor has attained full speed, a current will flow in the B B axis and produce a field along that axis. The winding $S_{2}$ can now be cut out and the motor will continue to run, the motor field being produced by the current in the rotor along the $\mathrm{B} B$ axis. In all cases of a field being produced by the rotor, it is important to bear in mind that the axis of the flux coincides with the axis of the brushes, since the magnetic reluctance is practically uniform all round the gap.

The vector diagram of the Atkinson motor is shown in Fig. I (c). Starting with the applied voltage $\mathrm{V}$, we have the transformer flux $\mathrm{N}_{2}$ practically in quadrature with it, and the transformer E.M.F., $\mathrm{E}_{\mathrm{T}}$ lagging $90^{\circ}$ behind the flux. Due to the rotation of the rotor conductors in this flux we have $E_{B}$ (the E.M.F. in the $B B$ axis) in phase with $N_{1}$, and causing the current $I_{B}$ to flow in the $B$ axis. Owing to the high self-induction of the armature along this axis, $I_{B}$ lags by a large angle behind $E_{B}$, and the motor flux $\mathrm{N}_{2}$ set up by it will be almost in quadrature with $E_{B}$. Due to rotation in $N_{2}$ we have the back E.M.F., $E_{A}$, opposing $E_{T}$. The resultant of $E_{T}$ and $E_{A}$ is $E_{R}$, which is the vectorial sum of $I R$, the drop of pressure due to resistance, and $E_{s}$, the inductive drop in the $A A$ axis. The armature current $I_{A}$ is in phase with IR. The resultant of the current $I_{A}$ and the stator current $I_{S}$ must be the magnetizing current $I_{O}$ which is necessary to produce the flux $\mathrm{N}_{1}$ along the $\mathrm{AA}$ axis; and from the position of the vector $I_{A}$ the power factor of the stator is necessarily low. It will be seen from the figure that there is a large phase displacement between the armature current $I_{A}$ and the motor flux $N_{2}$, thus necessitating a large armature current for a small torque and limiting the output of the motor.

The conditions may be somewhat improved by adding self-induction along the $\mathrm{B} B$ axis by means of an external choking coil. The effect of this is to make $I_{B}$ lag still more behind $E_{B}$, consequently displacing $N_{2}$ still farther 
and decreasing the angle between the motor flux $\mathrm{N}_{2}$ and the armature current $\mathrm{I}_{\mathrm{A}}$. It will be noticed also that by displacing $\mathrm{N}_{2}$ still farther back $E_{\mathrm{A}}$ is also moved, and this brings $I_{A}$ still more into phase with $\mathrm{N}_{2}$. By adding inductance in this manner $I_{B}$ is necessarily reduced, and consequently the field $\mathrm{N}_{2}$ is weakened and the speed increased. This method can be used to a limited extent for speed control.

Fig. 2 shows the curves of performance of this motor both with and without added self-induction in the B B axis. It will be observed that the output is small, the maximum being about 3 b.h.p. without, and 4 b.h.p. with, additional self-induction. The efficiency in the first case only reaches $5 \mathrm{I}$ per cent, and the power factor $0_{5} 5$. These are increased to 58 per cent and 0.62 respectively by adding self-induction. It will be noticed that the current in the $\mathrm{A} \mathrm{A}$ axis reaches about 100 amperes in each case, and that it is increasing very rapidly. It is obvious that and flux should be in phase at full load although the power factor is thereby somewhat reduced. This point is further discussed in connection with the curves of performance of the motor. The compensating E.M.F. is in phase with $E_{\mathrm{T}}$, and can therefore be induced directly by transformer action from the main stator winding. A winding, $\mathrm{S}_{3}$, consisting of a few turns is placed in the same slots as the main winding, and is connected across the brushes $\mathrm{B} B$ in place of the short-circuit used in the Atkinson connection.

The connections of this motor are shown in Fig. 3. At starting the windings $S_{1}$ and $S_{2}$ are connected in series by means of the switch $\mathrm{H}$, the $\mathrm{B} \mathrm{B}$ brushes being opencircuited. The machine starts up as a repulsion motor as previously explained. When up to speed the resistance $R$ in the $B$ B circuit is cut out, and at the same time the switch $\mathrm{H}$ is moved over the stops, cutting out the winding $S_{2}$ in three steps. To reverse the direction of

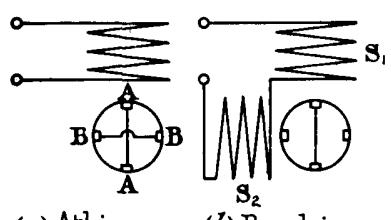

(a) Atkinson (b) Repulsion

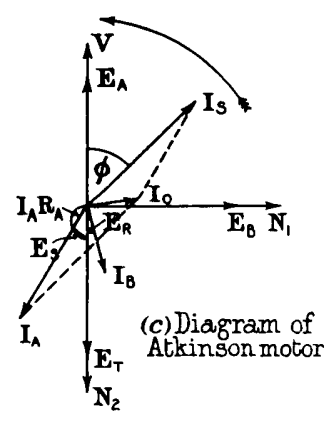

FIG. I.

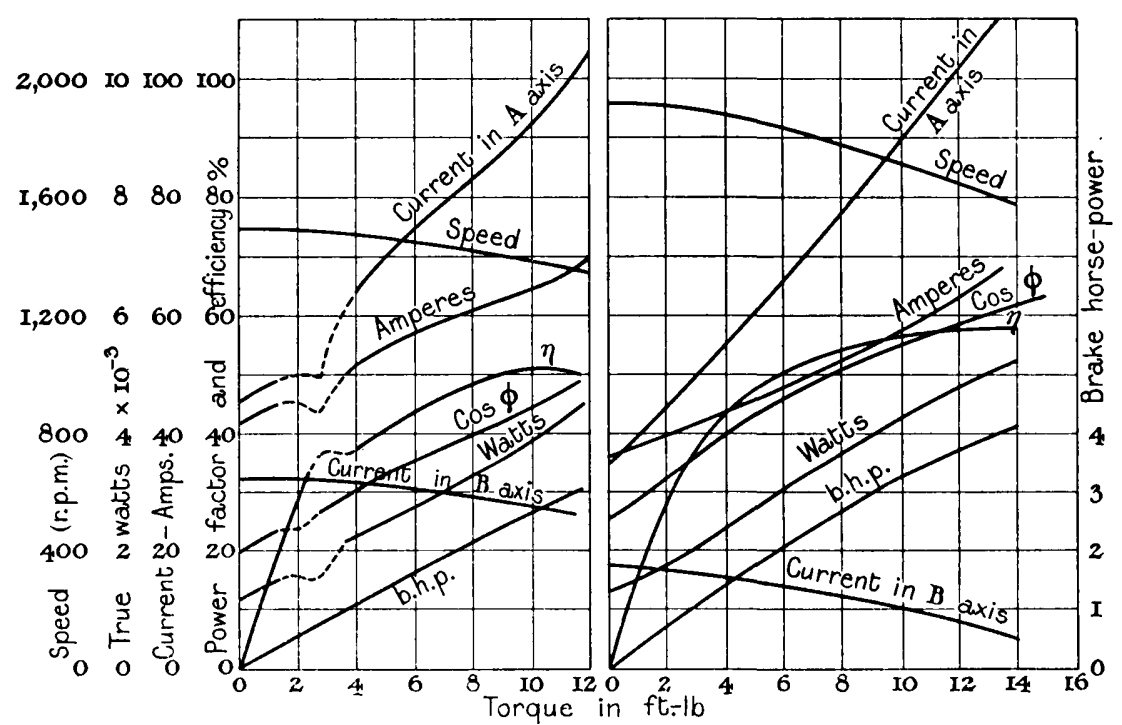

FIG. 2.

(1) Athinson Motor.

(2) Atkinson Motor, with extra self-induction in B B axis.

in this form the motor cannot be considered as a commercial machine. The performance of the motor is, however, greatly improved by the addition of the compensating device invented by Mr. Fynn, and described by him in a paper read before the Institution in 1906.*

The method adopted is to add a small E.M.F., $E_{c}$, in the $\mathrm{B} \mathrm{B}$ axis in quadrature with $\mathrm{E}_{13}$. Referring to Fig. 3, the result is to shift $\mathrm{E}_{\mathrm{B}}$ to $\mathrm{E}_{\mathrm{B}}{ }^{\prime}$. The consequent displacement of $\mathrm{N}_{2}$ and $\mathrm{E}_{\mathrm{A}}$ causes $\mathrm{N}_{2}$ to lag in phase behind $\mathrm{I}_{\mathrm{A}}$, and since the stator current $I_{S}$ must always be determined by the resultant of $I_{A}$ and $I_{O}$, it is now brought nearly into phase with the applied voltage. By suitably choosing the amount of compensation the power factor may be increased to unity at any particular load. This result is only possible, however, if there is a phase displacement between the flux $\mathrm{N}_{2}$ and the current $\mathrm{I}_{A}$; and as this current practically limits the output of the motor it is very desirable that this current

* V. Fyxs. A new single-phase commutator motor. Fournal I E.E., vol. 36, p. 324,1906 . rotation, the connections to $S_{2}$, and also to the compensating winding $\mathrm{S}_{3}$, are reversed.

Fig. 4 gives the result of a constant-voltage test on the motor thus connected, and it illustrates the striking improvement effected by the use of the compensating winding; for the same armature current the torque is doubled. The full-load efficiency has risen to 75 per cent, and the output of the motor is correspondingly increased. At no-load the stator current leads on the voltage, but as the lcad increases the phase displacement becomes less, the power factor being nearly unity at about half full load and then decreasing, although not very rapidly. As explained above, the power factor at any load depends entirely on the magnitude of the compensating E.M.F. and not on the dispersion coefficient as in the ordinary induction motor. Complete compensation can, however, only be attained at the expense of increased copper loss in the rotor. It will be observed that the current in the $\mathrm{B} B$ axis and therefore the motor flux $\mathrm{N}_{2}$ are nearly 
constant, being proportional to the speed. The armature current $I_{A}$ depends on the load and the angle between $I_{A}$ and $N_{2}$, and since this phase angle decreases at first more rapidly than the load increases, $I_{A}$ falls to a minimum value, after which it increases with the load. After full load is reached this increase becomes very rapid, since the of his design, built by Messrs. Parkinson, of Leeds, and he has kindly given permission to publish the results.

This motor is shown diagrammatically in Fig. 5. The stator is wound with six salient poles, and the rotor is an ordinary continuous-current armature with three sets of bruthes on the commutator. The brush arrangement for
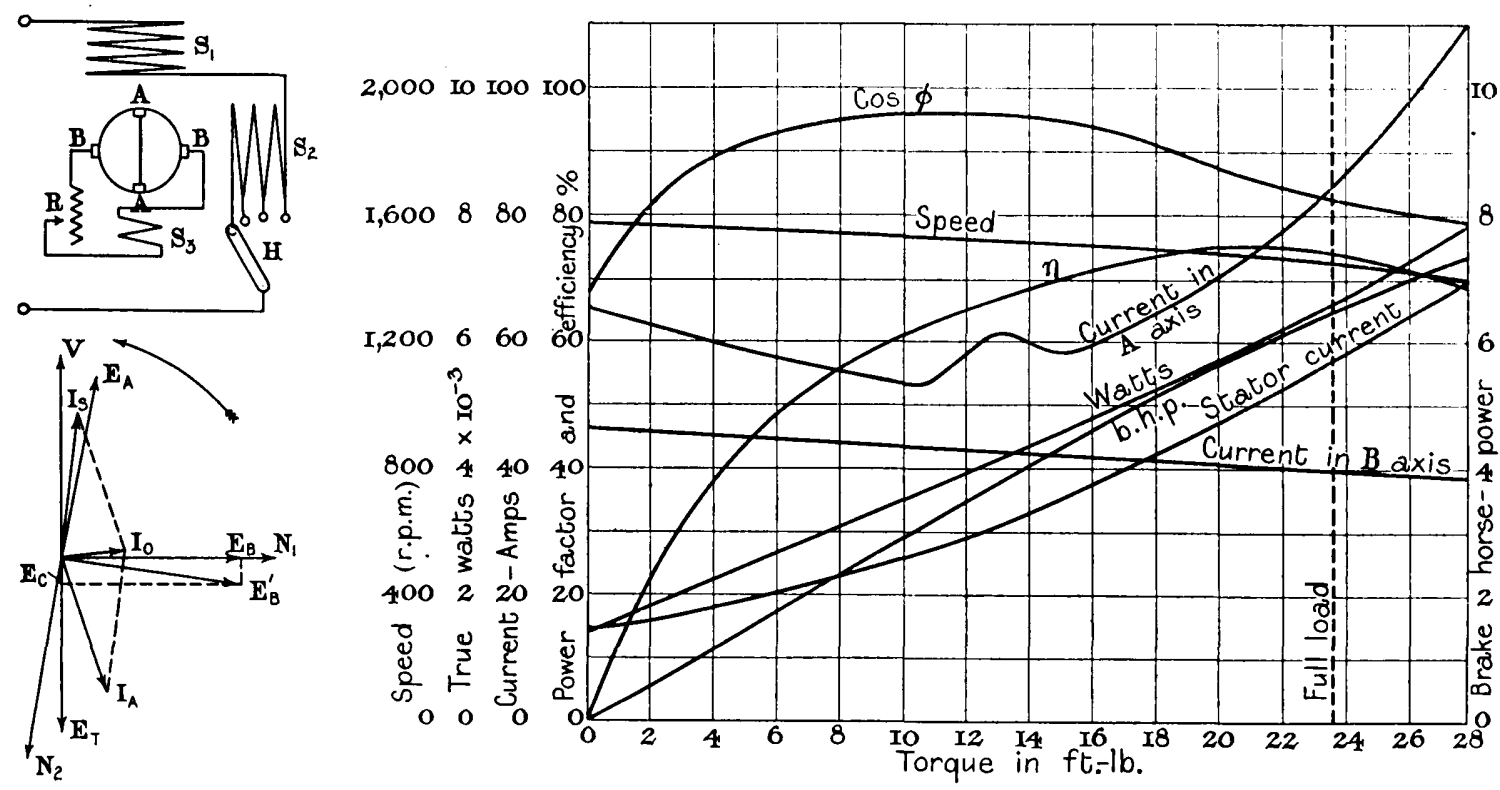

FIgs. 3 AND 4.-Fynn Motor.
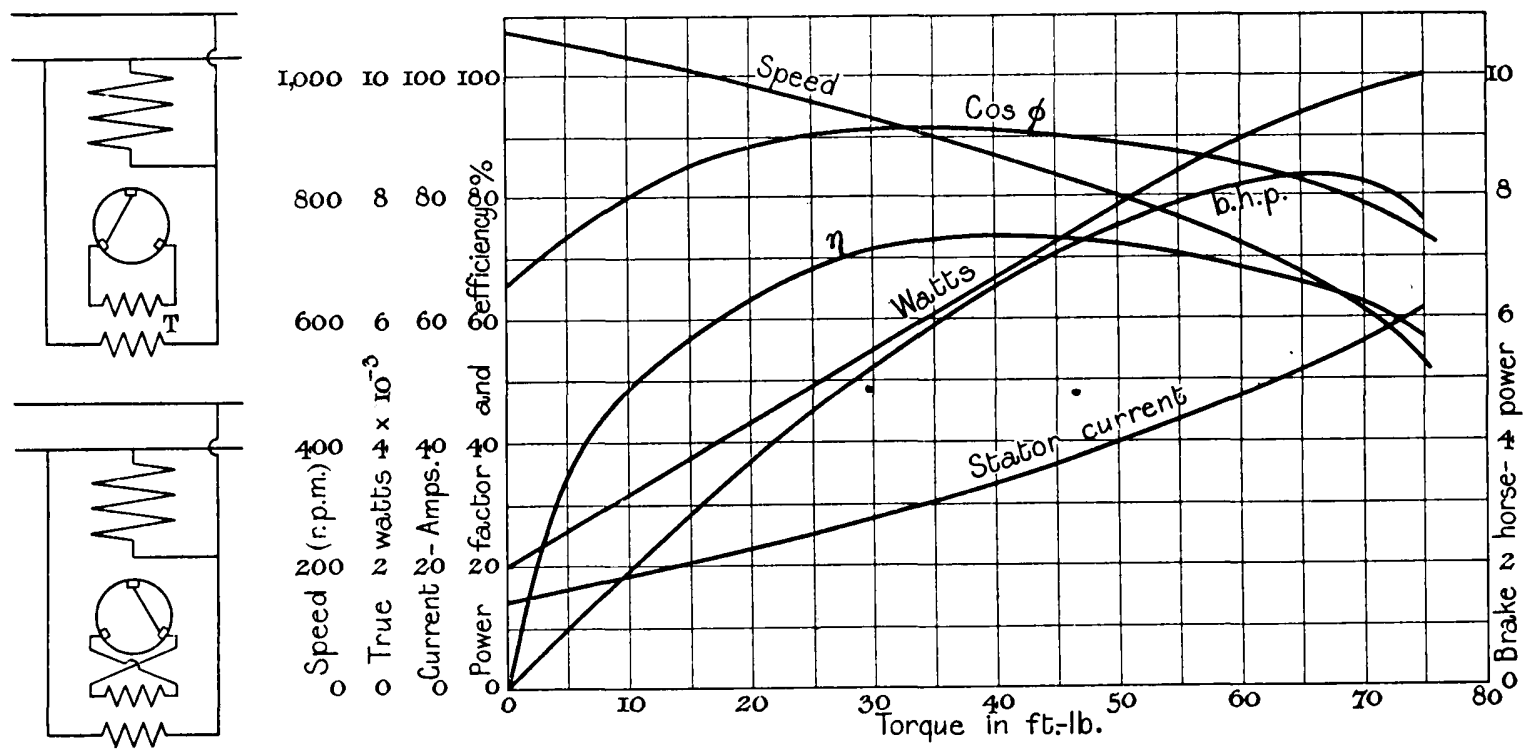

Figs. 5 AND 6.-Creedy Motor.

current is again out of phase with the flux, and consequently the efficiency begins to fall off. At no-load the speed is slightly above synchronism, falling uniformly about io per cent over the whole range of load.

In addition to the tests carried out on the Fynn motor, the authors had the privilege of assisting Mr. Creedy in carrying out some tests on a new commutator motor a similar two-pole motor is shown in the figure. The compensation on this motor is provided by an external transformer $T$, the primary of which is connected in parallel with the stator across the mains. With the secondary of this transformer disconnected we have an ordinary repulsion motor. With the transformer connected the compensating E.M.F. is introduced into what 
corresponds to the B B axis of the Atkinson motor, and raises the power factor to unity at some particular load. On account of the magnetizing current of the transformer, the power factor of the whole motor is somewhat lower than unity, reaching about $0^{\circ} 9 \mathrm{r}$ at full load. The motor having been designed especially for lift work has a
65 amperes. This current can be somewhat reduced by varying the amount of compensation, but the power factor suffers in consequence. In fact, by adjustment of the compensation the motor may be given any characteristic intermediate between shunt and series.

For the sake of comparison the original Fynn motor was
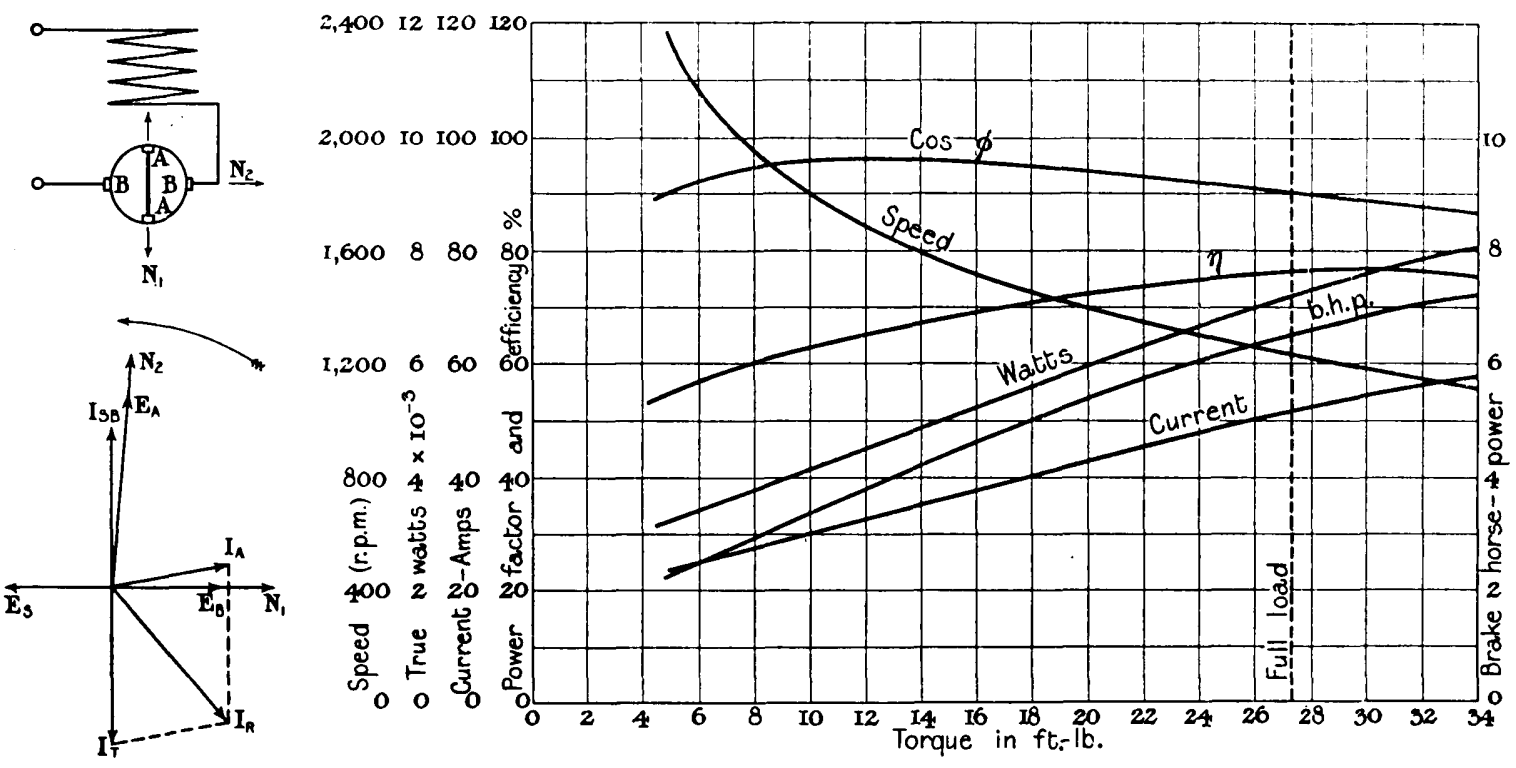

Figs. 7 AND 8.-Latour-Winter-Eichberg Motor.
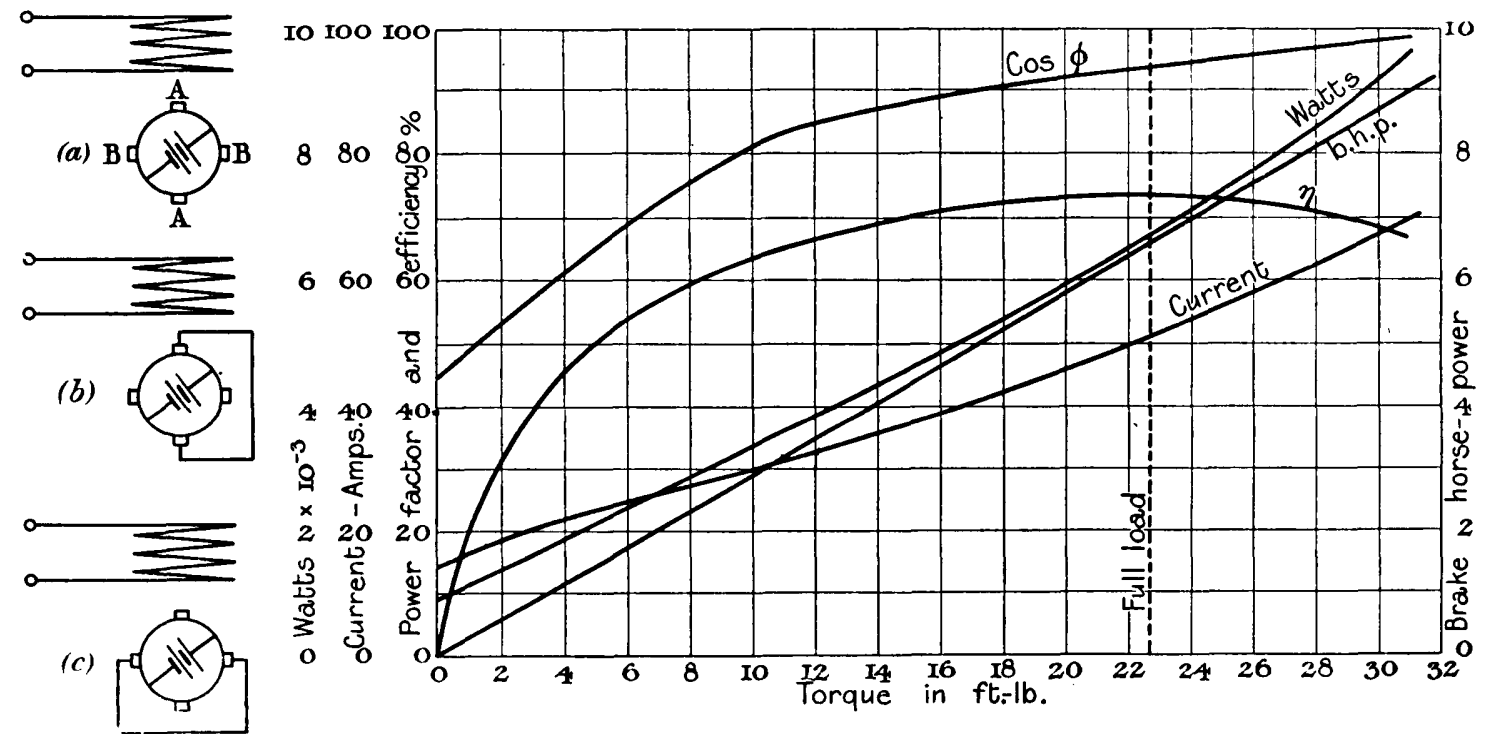

Figs. 9 AND I0.-Synchronous Motor.

very high starting torque-starting being effected by switching the motor straight on to the mains, thus simplifying the external connections.

The performance curves of this motor are shown in Fig. 6 . The efficiency at full load is about 74 per cent and the power factor o.9I. The starting torque at 220 volts - the working voltage of the motor-is about 75 lb.-ft., $2 \frac{1}{2}$ times full-load torque, with a current of next tested as a Latour-Winter-Eichberg motor. The connections and vector diagram are shown in Fig. 7 . The latter is taken from a paper read by Messrs. Page and Scott before the Students' Section,* in which this motor is fully dealt with. The authors therefore do not

* G. W. P. PAGE and G. J. Scotr. Single-phase commutator motors, especially the Latour-Winter-Eichberg type. Foumal I.E.E., vol. 47, p. 779 , I9I I. 
propose to deal here with this type in detail. The performance curves are given in Fig. 8. This motor having a series characteristic the speed decreases rapidly as the load increases. At about synchronous speed the motor has its maximum power factor of $0^{\circ} 97$. The efficiency at full load reaches 76 per cent at a power factor of 0.90 .

It has been previously mentioned that the motor is provided with slip-rings connected to equidistant points tion as the slip-ring connections passed under the brushes, a choking coil was connected in series with the continuouscurrent source of supply.

It was hoped that by running the machine as a synchronous motor a greater efficiency would be obtained, as the iron losses are a minimum at synchronous speed; but owing to the necessity for short-circuiting the $A$ A axis, and the consequent heavy $I^{2} R$ losses in the rotor, no improve-

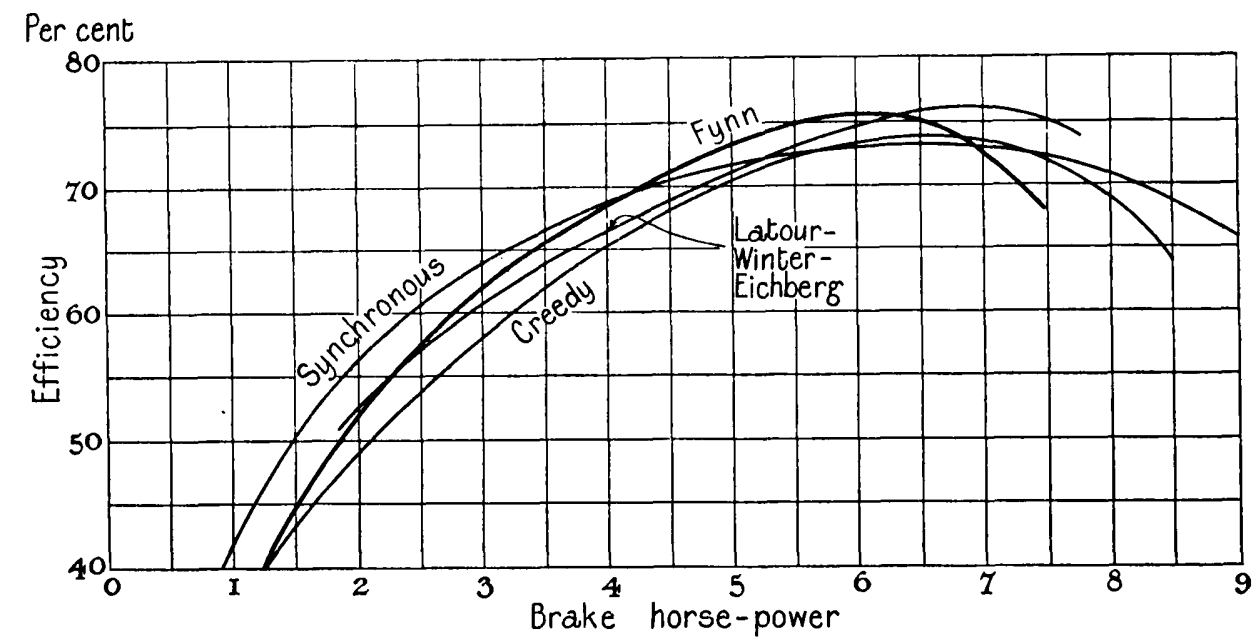

FIG. Ir.-Efficiencies.

in the armature. Brushes were fitted to two rings connected to diametrically opposite points, and the machine was run as a synchronous motor, continuous current being led into the rotor by means of these rings to form the field-magnet system. Connections were first made as shown in Fig. $9(a)$. Starting was effected as a repulsion motor, and when synchronous speed was reached the ment was effected in this direction. The experiment has some interest, however, as an example of a self-starting synchronous motor. The power factor can of course be varied at will by altering the amount of the continuouscurrent excitation. The motor was also tried with the B B axis short-circuited, the idea being that this would act as a compensating winding and prevent the phase-swinging of

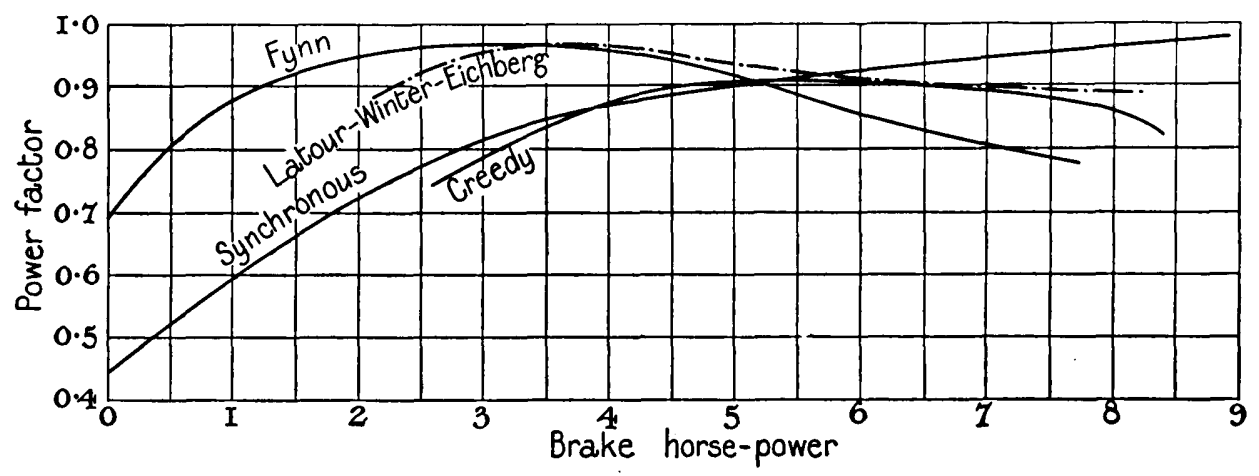

FIG. 12.-Power Factors.

continuous current was switched on to the rotor and the auxiliary winding cut out through a resistance. It was found to be impossible to load the motor to any extent without pulling it out of step owing to the high reactance of the stator. The A A axis was therefore short-circuited as shown in Fig. $9(b)$ to reduce the stator impedance. In this way satisfactory running was obtained up to well above full-load output. In order to prevent any ill-effects from the short-circuiting of the continuous-current excita- the flux. This was unsatisfactory as the motor pulled out of step in the same way as when there was no short-circuit. Excessive sparking prevented the running of the motor with both axes short-circuited.

The performance curves of the synchronous motor with the A A axis short-circuited are shown in Fig. Io. To obtain the necessary torque at heavy loads the motor was over-excited and so a leading power factor was obtained, viz. 0.45 at no load, rising to $0^{\circ} 93$ at full load and nearly 
unity at 40 per cent overload. The efficiency reached 73 per cent at full load.

In Fig. I the efficiencies of the Fynn, Latour-WinterEichberg, synchronous, and Creedy motors are shown together, plotted with the brake horse-power as abscissa. It will be seen that the efficiencies in each case are nearly the same, varying from 73 per cent to 75 per cent at full load, which figures compare fairly favourably with those of single-phase induction motors of the same horse-power. Efficiencies of about 85 per cent are obtained with Fynn and Creedy motors of 30 to 50 h.p.

The power factors are compared in the same way in Fig. 12 and range from $0^{\circ} 85$ to $0^{\prime} 92$ at full load, the figures for the Fyun and Latour-Winter-Eichberg motors being somewhat higher at about half load. The synchronous motor, as explained before, was taking a leading current, as was also undoubtedly the case with the Fynn and Latour-Winter-Eichberg motors at light loads. Of course the synchronous motor could be adjusted to give nearly unity power factor at all loads, the curve given referring
The losses occurring in the motor may be classified as follows:-(a) Resistance losses in stator and rotor; $(b)$ brush contact and resistance losses; $(c)$ friction and windage losses; $(d)$ eddy current and hysteresis losses, including under the former title the losses due to currents circulating in the coils short-circuited under the brushes.

'The losses under heading ( $a$ ) merely resolve themselves into accurate determinations of the resistances of the various circuits and the currents flowing in them, and therefore require no special consideration.

(b) The brush losses were experimentally determined in the following manner:-The Fynn machine was driven by means of a belt from an adjustable-speed continuouscurrent motor. A pair of brushes on the same spindle were used for the test, one brush-holder being in contact with the spindle and the other insulated from it. A measured continuous current was led in at one brush, along the commutator segments, and out at the other brush, and the drop of potential in the two brushes in

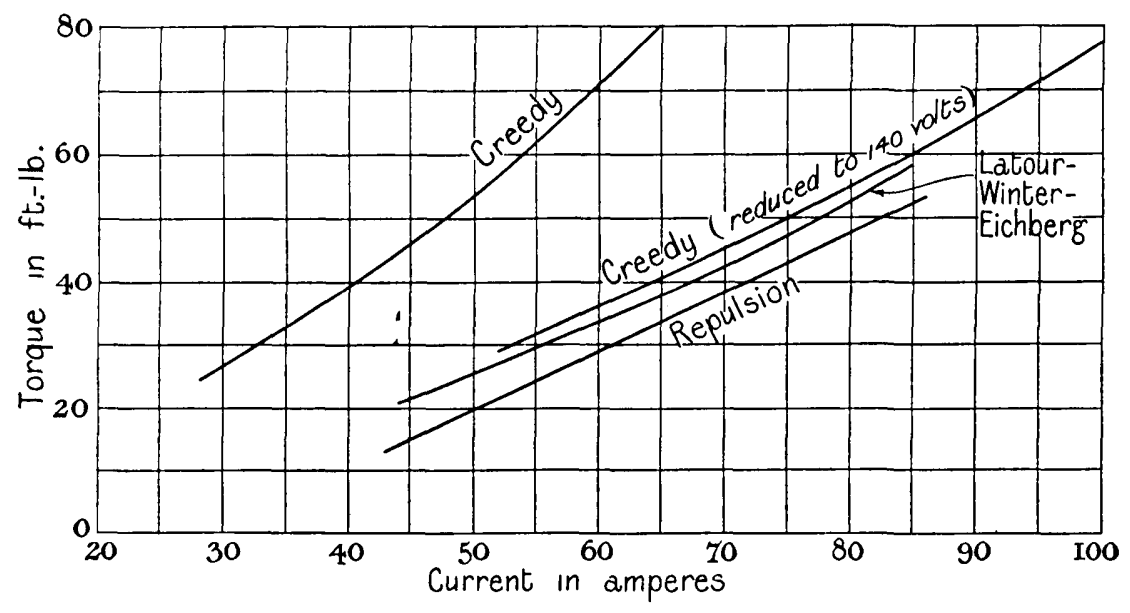

FIG. 13, -Starting Torques.

only to the case where the excitation is kept constant throughout.

The starting performances of the Fynn, Latour-WinterEichberg, and Creedy motors are shown in Fig. 13, the Fynn motor starting as a plain repulsion motor. The Creedy motor being a 220-volt machine, the equivalent currents at a pressure of 1 fo rolts are plotted in this case. The starting torque is plotted with the values of the current as abscissa. It will be seen that with the Latour. Winter-Eichberg connection a considerably higher torque is obtained for the same current than with the repulsion-motor connections. This is merely a question of the relative strengths of the two flux components in the repulsion motor, and, of course, leakage is less in the Latour-Winter-Eichberg machine as the field is produced directly by the rotor. The latter gives twice full-load torque with about $\mathrm{I} \frac{1}{2}$ times full-load current. The Creedy motor gives about $2 \frac{1}{2}$ times full-load torque with twice fullload current.

Experiments were carried out to determine the proportion of the various losses in the Fynn motor when connected according to the different methods described. series was measured with a voltmeter. In this way a series of readings was taken at various speeds for a number of constant values of the current. As the segments pass under the brushes the resistance varies, so that the current as measured on an oscillograph would appear like a continuous current with a high-frequency alternating current superposed on it, and the voltage would follow the same variations. Moving-coil instruments read the average values of the current and voltage, and therefore the product differs from the true power. To eliminate this source of error a choking coil was connected in series with the continuous-current supply, thus damping out the highfrequency oscillations in the current. The curves showing the brush loss are given in Fig. 14 ; and from these curves the losses per pair of brushes at any required speed and current can be read off. The losses increase very rapidly at high speeds, probably owing to the increase of the contact-resistance due to mechanical vibration.

(c) To determine the friction and windage losses a continuous-current motor was calibrated for various speeds and was used to drive the Fynn motor by means of a light canvas belt. Readings were taken of the input 
to the motor when driving the Fynn motor at various speeds, and the difference between the power under these conditions and that required to drive the continuouscurrent motor light gives the total windage and friction losses fairly accurately. Brush friction was also separated by taking reactings with and without the brushes. The friction loss curves are shown in Fig. 15 .

(d) The exact determination of the separate components of the iron loss in these motors is extremely difficult, as

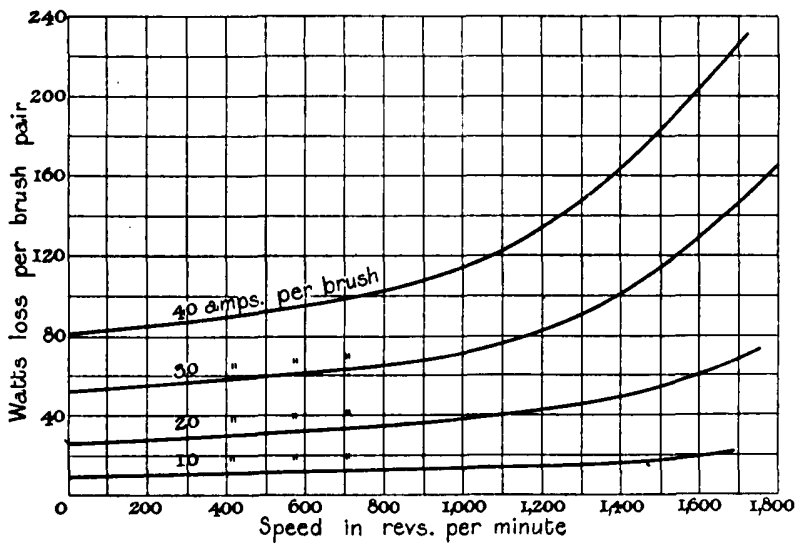

Fig. 14.-Brush Contact and Resistance Losses.

there are so many factors to be considered. With the Atkinson or Fynn connections there will be :-(I) Eddy current and hysteresis losses along the $\mathrm{A} A$ axis due to the transformer flux $\mathrm{N}_{\mathrm{I}}$ (with a constant applied voltage the stator loss due to this flux will be constant, but the rotor loss depends on the speed). (2) Similar losses along the B B axis caused by the motor flux $\mathrm{N}_{2}$ (these losses are a function of the speed). (3) Losses in the rotor caused by

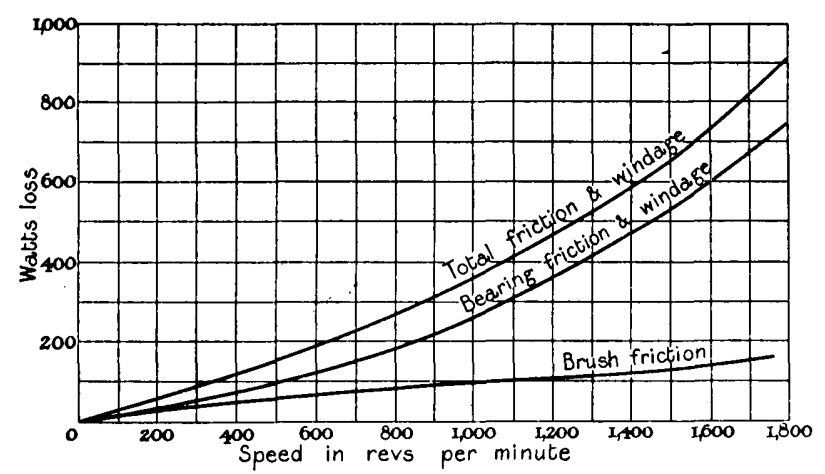

Fig. 15.-Friction and Windage Losses.

the cutting of these fluxes at all speeds except synchronous speed. The fluxes $\mathrm{N}_{2}$ and $\mathrm{N}_{2}$ being nearly at right angles in time relation as well as in space, may be considered as forming a rotating field, which will be elliptical except at synchronous speed. At the latter speed the two fluxes are practically equal, and the rotating field will therefore be circular. Now this field always rotates at the specd corresponding to the supply frequency, and consequently if the rotor is running below synchronism there will be a hysteretic drag in the direction of rotation, whilst above that speed this torque is reversed. The rotor iron losses depend on the relative speed of the rotor and the rotating field, so that at synchronous speed they should be nearly zero. In addition to the above there are also the pulsation losses in the stator and rotor teeth, so that it will be seen that an accurate separation of the losses would be exceedingly difficult. For comparative purposes it will be sufficient if the total iron losses are known at any speed.

In order to determine these losses, the motor was driven as in the friction and windage test, and the power supplied to the driving motor was measured. An alternating current at $50 \sim$ was led into the $\mathrm{A} A$ axis of the Fymn rotor through the current coil of a wattmeter $W_{x}$. The pressure coil of this instrument was connected to the terminals of the stator winding $S_{x}$ on this axis, and the current in this axis was maintained constant at a fixed value for each test. Under these conditions the wattmeter reads the power supplied minus the copper losses in the A A axis, for the voltage differs in phase by $90^{\circ}$ from the flux, since it is induced by the change of the latter.

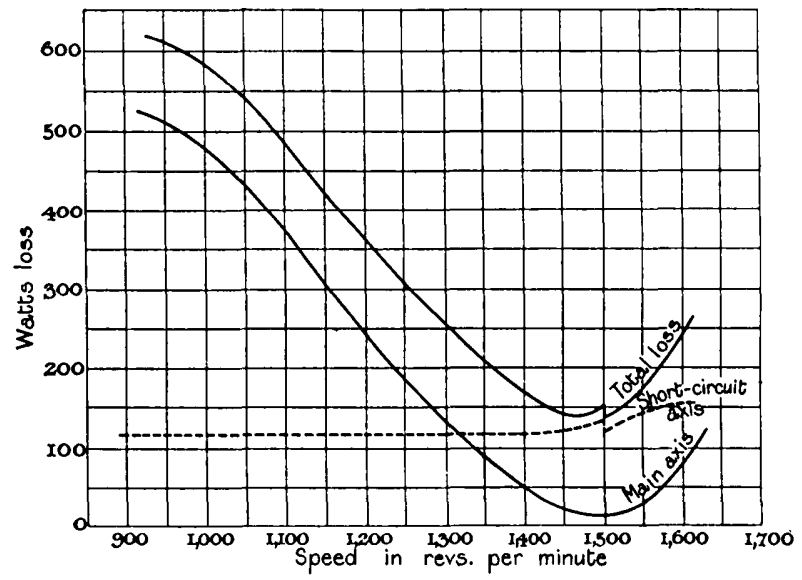

Fig. 16.-Iron Losses.

If the flux were in phase with the current the wattmeter reading would therefore be zero, but since the iron losses cause the flux to lag behind the current the wattmeter measures these losses. The readings have of course to be multiplied by the ratio of the number of secondary to primary turns. It was verified experimentally that the circulating currents in the short-circuited coils also alter the phase of the flux, so that these losses are also measured by the wattmeter. In a similar way the wattmeter $W_{2}$ measures the losses along the $\mathrm{B} \mathrm{B}$ axis. The driving motor supplies the power necessary to overcome the resistance and iron losses in the $B$ B axis, and also the pulsation losses.

The results of these tests are shown in Fig. I6. The total loss is taken as the sum of $W_{1}$ and $W_{2}$. As a check, the total power supplied to the Fynn motor, i.e. the reading of $W_{I}$ and the input to the driving motor above that required to drive the Fynn machine unexcited, must be equal to the total iron losses and the resistance loss in the $\mathrm{B} \mathrm{B}$ axis. The values obtained in this way were found to agree well with those obtained by the first method. At constant voltage the stator iron loss along the $\mathrm{A} \mathrm{A}$ axis is practically constant, whilst in the $\mathrm{B} \mathrm{B}$ axis it increases 
with the speed, since the flux in this axis depends on the speed. The rotor losses, however, are practically zero at synchronous speed, but increase very rapidly on either side of this speed. This is due to the fact that the rotor losses are largely due to the circulating currents in the short-circuited coils, and therefore for constant density vary as the square of the frequency, the latter being the difference between the synchronous speed and the actual speed.

The accompanying table shows the actual losses in the available for the tests, and this makes the losses somewhat higher than they would otherwise have been. Friction and windage account for about 40 per cent of the losses. The brush friction forms about one-third of the total friction and windage loss in each case.

Single-phase commutator motors may be put to practically the same uses as small continuous-current motors, their only serious rival for small outputs being the singlephase induction motor. Their lower efficiency and higher cost are somewhat of a disadvantage, but their high

\begin{tabular}{|c|c|c|c|c|c|c|c|c|c|}
\hline & & \multicolumn{2}{|c|}{$\begin{array}{l}\text { Atkinson. At } 3 \text { b.h.p., } \\
\text { I,350 r.p.m. }\end{array}$} & \multicolumn{2}{|c|}{$\begin{array}{l}\text { Fynn. } 6 \text { b.h.p., } \\
1,480 \text { r.p.m. }\end{array}$} & \multicolumn{2}{|c|}{$\begin{array}{l}\text { Latour-Winter- } \\
\text { Eichberg. } 6 \text { b.h.p., } \\
\text { I,320 r.p.m. }\end{array}$} & \multicolumn{2}{|c|}{$\begin{array}{l}\text { Synchronous. } 6 \text { b.h.p., } \\
\text { r,500 r.p.m. }\end{array}$} \\
\hline & & Watts & $\begin{array}{l}\text { Per Cent } \\
\text { of Total } \\
\text { Loss }\end{array}$ & Watts & $\begin{array}{l}\text { Per Cent } \\
\text { of Total } \\
\text { Loss }\end{array}$ & Watts & $\begin{array}{l}\text { Per Cent } \\
\text { of Total } \\
\text { Loss }\end{array}$ & Watts & $\begin{array}{l}\text { Per Cent } \\
\text { of Total } \\
\text { - Loss }\end{array}$ \\
\hline \multirow[t]{2}{*}{ Copper losses } & $\begin{array}{l}\text { Stator } \\
\text { A A Axis } \\
\text { B B Axis } \quad \ldots \\
\text { Comp. winding }\end{array}$ & $\begin{array}{r}480 \\
270 \\
20 \\
-\end{array}$ & $\begin{array}{r}22 \\
13 \\
1 \\
-\end{array}$ & $\begin{array}{r}250 \\
122 \\
46 \\
40\end{array}$ & $\begin{array}{r}16 \\
8 \\
3 \\
2\end{array}$ & $\begin{array}{r}224 \\
162 \\
54 \\
-\end{array}$ & $\begin{array}{r}14 \\
10 \\
3 \\
\end{array}$ & $\begin{array}{l}230 \\
220 \\
- \\
-\end{array}$ & $\begin{array}{l}\text { I4 } \\
\text { I3 } \\
-\end{array}$ \\
\hline & Total & 770 & 36 & 468 & 29 & 440 & 27 & $45^{\circ}$ & 27 \\
\hline \multirow[t]{2}{*}{ Brush losses } & $\begin{array}{ll}\text { A A Axis } & \ldots \\
\text { B B Axis } & \ldots\end{array}$ & $\begin{array}{r}300 \\
60\end{array}$ & $\begin{array}{r}14 \\
3\end{array}$ & $\begin{array}{l}240 \\
130\end{array}$ & $\begin{array}{r}I_{5} \\
8\end{array}$ & $\begin{array}{l}240 \\
136\end{array}$ & $\begin{array}{r}\text { I5 } \\
9\end{array}$ & $\underline{468}$ & 28 \\
\hline & Total $\quad \ldots 1$ & 360 & I7 & 370 & 23 & 376 & 24 & 468 & 28 \\
\hline \multirow[t]{2}{*}{$\begin{array}{l}\text { Windage and } \\
\text { friction }\end{array}$} & Brush friction & II 5 & 5 & $15^{\circ}$ & 9 & I 10 & 7 & 156 & 9 \\
\hline & Total & $55^{\circ}$ & 26 & 640 & 40 & 540 & 35 & 650 & 39 \\
\hline $\begin{array}{l}\text { Iron losses and cir- } \\
\text { culating currents }\end{array}$ & - & 480 & $2 I$ & 130 & 8 & 200 & 14 & IIO & 6 \\
\hline $\begin{array}{lr}\text { Total losses } & \ldots \\
\text { Output } \ldots & \ldots \\
\text { Input } \ldots & \ldots \\
\text { Efficiency } & \ldots \\
\text { Observed } & \text { effici- } \\
\text { ency } \quad \ldots & \ldots\end{array}$ & $\begin{array}{l}\overline{-} \\
\overline{-} \\
-\end{array}$ & \multicolumn{2}{|c|}{$\begin{array}{c}2,160 \\
2,240 \\
4,400 \\
51 \text { per cent }\end{array}$} & \multicolumn{2}{|c|}{$\begin{array}{c}1,600 \\
4,480 \\
6,080 \\
74 \text { per cent } \\
74^{\cdot} 6\end{array}$} & \multicolumn{2}{|c|}{$\begin{array}{c}1,560 \\
4,480 \\
6,040 \\
74 \text { per cent }\end{array}$} & \multicolumn{2}{|c|}{$\begin{array}{c}I, 680 \\
4,480 \\
6,160 \\
72 \cdot 5 \text { per cent }\end{array}$} \\
\hline
\end{tabular}

various circuits, etc., of the motor when running as an Atkinson, Fynn, Latour.Winter-Eichberg, or synchronous motor, and also the separate losses as a percentage of the total losses in each case. Except for the Atkinson connection, in which the maximum output was 3 b.h.p., these are calculated for an output of 6 b.h.p., which is about the normal full load of the motor. In the last three cases it is interesting to observe that the efficiencies are nearly the same, although the losses are made up in rather different ways. In all cases the brush losses form a very considerable proportion of the total, owing to the heavy rotor currents and high speed. The motor should have four brushes per spindle on the A A axis, but only three were starting torque gives them a decided advantage for crane and lift work and for driving machinery where high starting torques are required, and they are being manufactured in increasing numbers for these purposes. They are practically the only single-phase motors which can be used for traction work, the plain series type and the Latour-Winter-Eichberg being favoured for this use.

Another great advantage of this type of motor is that it lends itself readily to speed regulation, the speed not being practically restricted to synchronism as is the case with the induction motor. There are several methods of varying the speed of these motors, one of them being to connect an inductance in circuit with the B B axis. The 
effect of this is to weaken the motor field, and the machine must therefore run faster in order that the back E.M.F. due to rotation in this flux may attain a sufficient value to restore the equilibrium of E.M.F.'s in the rotor. This method is illustrated in the second test on the Atkinson motor, where the additional inductance in the $B$ B axis caused the speed to rise from I,500 to I,900 r.p.m. A resistance cannot be used for this purpose as the current in the B B axis must lag by nearly $90^{\circ}$ behind the voltage for satisfactory working, and any additional resistance would naturally decrease this angle. Another method is to supply an extra voltage to the A A axis either by means of a tapping on the stator winding or an auxiliary transformer. This method is analogous to increasing the voltage applied to the armature of a continuous-current motor. $A$ third method is to place an extra coil on the B B axis, connected in series with the brushes on this axis, the coil being connected so that the flux produced by it opposes the motor flux, the effect being similar to that produced by the first method. All these devices tend to raise the speed above synchronism and have been used in practice with good results, but it is more difficult to lower the speed. Any departure from synchronous speed, however, increases the losses in the rotor as the circulating currents and iron losses increase rapidly.

Among the chief disadvantages of these commutator motors are their higher initial and running costs-the commutator of course requiring a certain amount of attention - and their liability to sparking troubles. Sparking on the Fynn motor was noticeable at starting and at heavy loads, probably owing to the fact that soft graphite brushes are used, which although reducing the brush friction and contact losses tend to increase the circulating currents and the amount of sparking; but under normal loads the machine was as sparkless as the average contiuuouscurrent motor. The Creedy motor, provided with hard carbon brushes, ran sparklessly at all loads, starting under twice full-load torque with no sign of sparking.

Since the experiments described were made, the authors have assisted in testing a Creedy motor with a variablespeed shunt characteristic, the range of speed being from 600 to 900 r.p.m. This motor is one of a batch designed for the driving of printing presses, but considerations of time prevent the inclusion of the results in this paper.

In conclusion the authors desire to express their thanks to Professor 'T. Mather of the City and Guilds College for permission to carry out the tests in the laboratories of the College, and to Mr. Creedy for allowing them to publish the results of the tests on his motors.

\section{APPENDIX.}

Details of Construction, etc., of Fynn Single-phase Commutator Motor. I40 Volts, 57 Amperes, $50 \mathrm{~N}$, I,430 R.P.M.

Rotor.

4-pole series-wound. Number of slots $=39$.

Number of segments $=117$. Six conductors per slot.

Number of conductors $=234$. Size of conductors $=0.15 \times 1 \mathrm{~cm}$.

Circumference of rotor $=8 \mathrm{r} \mathrm{cm}$. Diameter $=$ $25^{\circ} 8 \mathrm{~cm}$.

Axial length $=12.8 \mathrm{~cm}$.

Laminations per $\mathrm{cm} .=2 \mathrm{I}$.

Diameter of commutator $=19.3 \mathrm{~cm}$.

Size of slots $=\mathrm{I} \times 2.75 \mathrm{~cm}$.

Opening of slots $=0.3 \mathrm{~cm}$.

Gap length $=0^{\circ} \mathrm{I} \mathrm{cm}$.

Stator.

Bore $=26 \mathrm{~cm}$. External diameter $=42 \mathrm{~cm}$.

Number of stator slots $=36$.

Size of slots $=1.7 \times 2.3 \mathrm{~cm}$.

Slot opening $=0.36 \mathrm{~cm}$.

Axial length $=12 \cdot 8 \mathrm{~cm}$.

Brushes $15.3 \mathrm{~cm}$. apart, measured on arc.

Resistances of reindings.

Main stator winding $S_{\mathbf{t}}=0.103$ ohm.

Auxiliary stator winding $\mathrm{S}_{2}=0^{\circ} 08_{4} \mathrm{ohm}$.

Compensating stator winding $\mathrm{S}_{3}=0.022 \mathrm{ol} \mathrm{m}$.

Armature under brushes $=0^{\prime} 025 \mathrm{ohm}$.

Impedance of $\mathrm{B} \mathrm{B}$ axis $=2.26 \mathrm{ohm}$, with a current of 35 amps.

Power factor of B B axis $=0$ ror, with a current of 35 amps.

Ratios of turns.

$$
\begin{aligned}
& \frac{\text { Main winding }}{\text { Compensatıng winding }}=\stackrel{\text { IO }}{I} \\
& \frac{\text { Main winding }}{\text { Rotor along A A axis }}=\frac{1 \cdot 9}{I} \\
& \frac{\text { Auxiliary winding }}{\text { Rotor along B B axis }}=\frac{I 04}{I}
\end{aligned}
$$

Brushes.

Morganite. 4 brushes per spindle A A axis.

$$
2 \text { " " B B, }
$$

Brush area $=2 \cdot I$ sq. $\mathrm{cm}$. per brush. 